\title{
STRATEGIES FOR BI ACCEPTANCE: CHALLENGES AND SOLUTIONS
}

\author{
DOI: 10.17261/Pressacademia.2018.888 \\ PAP- V.7-2018(41)-p.237-240
}

\section{Naciye Guliz Ugur ${ }^{1}$, Aykut Hamit Turan ${ }^{2}$}

${ }^{1}$ Sakarya University, School of Business, Sakarya, Turkey. ngugur@sakarya.edu.tr, ORCID: 0000-0003-2364-5445

${ }^{2}$ Sakarya University, School of Business, Sakarya, Turkey.

ahturan@sakarya.edu.tr, ORCID: 0000-0002-8855-4643

To cite this document

Ugur, N. G., Turan, A. H. (2018). Strategies for Bl acceptance: challenges and solutions. PressAcademia Procedia (PAP), V.7, p.237-240. Permemant link to this document: http://doi.org/10.17261/Pressacademia.2018.888

Copyright: Published by PressAcademia and limited licenced re-use rights only.

\section{ABSTRACT}

Purpose- The purpose of this study is to propose recommendations for organizations on creating strategies for BI adoption at both the organizational and individual level to help maximize the value of the $B I$ investment.

Methodology- A significant literature review is conducted to identify key success factors. Thereafter, a model is introduced that will help to construct a strategy for $\mathrm{Bl}$ adoption at both the organizational and the individual level.

Findings- The solution model presented in this work is separated into three sections: people, process, and technology. Working with a $\mathrm{BI}$ team and collaborating with department leadership, the Analytics Advisor creates and successfully implements a BI solution through an iterative and agile process.

Conclusion- This paper has demonstrated how an organization can increase its Bl adoption rates by developing solutions for one department at a time. The solution enables the departments to implement a BI program that will provide value and a competitive advantage by improving the timeliness and quality of the decision-making process.

Keywords: Technology acceptance, business intelligence, BI adoption, critical success factors, solution model. JEL Codes: O14, O33, O30

\section{INTRODUCTION}

Organizations are investing in $\mathrm{BI}$ technologies to provide end users with the necessary tools that are needed in order to facilitate the decision-making process. Companies realize that these investments will create advantages such as higher profits, improved decisionmaking, and ultimately, a competitive advantage. The business intelligence industry is booming. In 2013 , businesses spent $\$ 14$ billion on $\mathrm{BI}$ software; by 2018 , experts predict that number to explode to $\$ 114$ billion (Stangarone, 2015). Yet as these investments continue to grow, $\mathrm{BI}$ user adoption rates have remained flat. Estimates show BI adoption rates among employees to be as low as $22 \%$ (Stangarone, 2015). In other words, businesses are investing in BI solutions more than ever; yet end users still are not utilizing the tools and taking advantage of these solutions. In order to maximize the value of their $\mathrm{BI}$ investments, organizations need to understand the reasons behind these low adoption rates and recognize the specific challenges that come with implementing a BI solution.

Business intelligence has numerous operational benefits such as efficiency improvement, process optimization, and time/cost savings. In addition, the strategic benefits of $\mathrm{BI}$ are the potential for increased profitability, increased market share, and increased customer satisfaction (Yogev, Even, \& Fink, 2013). Yet these benefits will not be realized without an increase in BI adoption rates which encompasses both the organizational and individual acceptance of the new applications. A number of BI project failures can be attributed to ineffective change management (Boyton et al., 2015). Williams and Williams (2003) posited that these failures point to a main problem in the BI industry - overstating the ease with which $\mathrm{BI}$ applications can be deployed and accepted within organizations. These overstatements often understate the adoption risk associated with BI applications.

As there are several challenges that organizations face while implementing a $\mathrm{BI}$ solution, the purpose of this study is to propose recommendations for organizations on creating strategies for $\mathrm{BI}$ adoption at both the organizational and individual level to help maximize the value of the $\mathrm{Bl}$ investment. These strategies will involve all levels of management from both the business and technical side with the overall strategy being business-driven and people-focused with particular emphasis on promoting a collaborative culture. This research will help leaders and managers gain insight into how to develop successful strategies and plans for user adoption and distribution of $\mathrm{BI}$ applications. 


\section{LITARATURE REVIEW}

For organizations embarking on the challenge of implementing a business intelligence (BI) program, understanding the factors involved in a successful implementation as well as the factors that lead to the acceptance and adoption of these new tools and processes is crucial.

Business intelligence (BI) was first introduced by the Gartner Group in the mid-1990s. The term was used to describe a variety of information technology (IT)-based tools and solutions designed to help organizations deal with the vast amounts of data accumulated from both internal and external sources (Isik et al., 2012). Traditional IT systems were efficient at capturing data and processing the data into information but they lacked the ability to provide flexible reporting functionality to better understand the information and its impact on the business. Organizations needed streamlined access to the underlying information in these systems and the ability to analyze that information in order to make operational decisions. The data from these transactional systems became a significant organizational asset that eventually would be used to provide an enterprise-wide unified view of the company and a competitive advantage for companies striving to compete in an ever-increasing global market (Woodside, 2011). This entire field emerged as business intelligence (BI) and includes the processes for gathering, storing, accessing, and analyzing data to help end-users make better decisions (Wixom et al., 2011).

Although BI has a number of capabilities including improving effectiveness, efficiency, and the quality of information (Mettler \& Vimarlund, 2009), the primary objective of BI systems is to improve the timeliness and quality of the decision-making process (Yeoh et al., 2008). A BI solution can take critical information from various source systems and integrate the data so that it can be analyzed collectively to support management's decision-making processes (Yeoh et al., 2008).

Companies expect to gain competitive advantages by adopting $\mathrm{BI}$ applications, yet these benefits can vary significantly depending on the individuals within the firm who are the ultimate users. While the decision to adopt $\mathrm{Bl}$ applications is typically done at the organizational level, the ultimate success of the BI program and the effective use of the BI applications are determined by individual users and, in particular, individual factors. Yoon et al., (2014) suggested that these factors could be categorized into four main areas: technology, individual difference, social influence, and situational constraints.

The technological factor is influenced by certain innovation characteristics such as relative advantage (RA), complexity, and compatibility (Yoon et al., 2014). Relative advantage refers to the degree to which the innovation is perceived as better than the idea it replaces. Complexity is the degree to which an innovation is perceived as difficult to understand and use; and compatibility refers to the degree to which an innovation is perceived as being consistent with existing values and experiences. Yoon et al., (2014) hypothesized that RA and compatibility would have a positive effect on an individual's intention to adopt BI applications while complexity would have a negative effect.

Individual differences such as motivation, personality, gender, education, etc., have been found to heavily influence individual technology acceptance. Yoon et al., (2014) suggested that both extrinsic and intrinsic motivation had a significant positive effect on an individual's intention to adopt a new BI application. While extrinsic motivation refers to doing something for the purpose of obtaining an external reward, intrinsic motivation involves doing something because it brings joy to the individual.

Social influence relates to the effect that coworkers and supervisors have on the individual's intent to adopt a BI application. If these individuals perceive that the $\mathrm{BI}$ application is useful and helpful, then a person is more likely to accept the system. Having committed management support and a dedicated sponsor for the $\mathrm{BI}$ project can help individuals see the expected benefits of implementing a $\mathrm{BI}$ program including such things as an increase in efficiency, process improvement, and time savings.

Situational constraint can also influence an individual's acceptance of new technology. For example, a person may not be willing to learn a new application if they believe that they do not have the skills or resources necessary to use that technology. An organization that encourages learning and development enables employees to be more willing to learn new things and apply them to their work; this environment has a positive influence on an individual's intent to accept a new technology.

End-user satisfaction also plays a key role in $\mathrm{BI}$ adoption at the individual level. Hou (2012) showed that system usage and end-user computing satisfaction (EUCS) both influence the individual performance by using the BI system. Hou (2012) provided empirical evidence that higher levels of EUCS leads to increased BI system usage as well as improved individual performance, and higher levels of EUCS leads to improved individual performance by using BI systems. In other words, the greater the use of the BI system, the more satisfied the user and the more satisfied the user, the greater the use of the $\mathrm{Bl}$ system. BI adoption in organizations has shown to increase individual productivity, improve efficiency by individuals accomplishing their tasks, and improve the quality of the decision-making process. Therefore, companies can improve overall employee performance when the user has a higher level of user satisfaction with BI systems (Hou, 2012).

Although $\mathrm{BI}$ has become a top priority for many organizations, not all $\mathrm{BI}$ initiatives have been successful in realizing the benefits of these systems. Most organizations begin their $\mathrm{BI}$ plan with high expectations of success yet many struggle to align their $\mathrm{BI}$ initiative to the strategic goals of the company. Indeed, as noted by Perez (2015), there are multiple organizational factors that can be attributed to the low $\mathrm{BI}$ adoption rate such as not getting buy-in from leadership, data quality and data integrity issues, and a lack of understanding the critical $\mathrm{BI}$ capabilities that define the success of BI applications. Understanding these factors is critical in order for companies to realize the full value of their BI solution.

A significant research has been conducted to identify the factors, which play a crucial role in BI adoption process. The output of the examined studies are summarized in the section of findings. The review helped us to generate a conceptual model by clustering the factors identified in the literature. 


\section{THEORETICAL MODEL}

Business intelligence solutions can provide both strategic and operational benefits to organizations through increased profits, improved efficiency, process optimization, and time/cost savings. In order to maximize these benefits, organizations need to ensure that these BI solutions are being successfully adopted by both employees and the organization. Developing a strategy to guarantee that the Bl solution will be utilized to the highest extent possible is a proactive approach to making sure that the tools and processes are embraced by everyone. The various issues that institutions face when implementing Bl solutions were identified in the literature review and a solution model was proposed in order to help alleviate some of these issues.

Understanding the factors that contribute to an organization's adoption of business intelligence practices is critical to the overall success of the BI program. Most firms hope to gain competitive advantages by implementing a BI program but these benefits are heavily influenced by individuals within the company who are the ultimate users. BI systems that are not utilized will not provide the expected returns that top management anticipates. Indeed, individual differences such as gender, personality, education, motivation, and cognitive style can have a profound influence on user acceptance of BI applications (Yoon et al., 2014).

The review of existing literature related to business intelligence (BI) indicated a need for improved $\mathrm{BI}$ adoption strategies in order to capitalize on the benefits of utilizing a BI solution. Businesses continue to invest millions of dollars in BI technologies to provide end users with the necessary tools that are needed in order to facilitate the decision-making process. Consequently, leaders expect a significant return on investment (ROI) from these $\mathrm{BI}$ solutions. Yet as these investments continue to grow, the $\mathrm{BI}$ user adoption rate remains flat. Estimates show BI adoption rates among employees to be as low as 22\% (Stangarone, 2015). In order to maximize the value of their BI investments, organizations need to develop strategies aimed at increasing the user acceptance of these tools at both the individual and the organizational level.

Business intelligence systems can provide organizations with a tool to analyze both historical and operational data to make informed business decisions. $\mathrm{BI}$ is unique in its potential to generate both strategic and operational value through the seamless integration of organizational data to support decision at all levels of the organization. The operational benefits include efficiency improvement, process optimization, and time/cost savings. The strategic benefits include the potential for increased profits, market share, and customer satisfaction (Yogev et al., 2013). However, organizations struggle with adopting new analytical solutions.

The adoption barriers are often not related to data and technology but rather are managerial and cultural. In fact, a leading obstacle to widespread $\mathrm{BI}$ adoption is a lack of understanding how to use analytics to improve the business (LaValle et al., 2011). In order to ensure that $\mathrm{BI}$ solutions are being used to the maximum extent possible, a business model is needed that will embed the BI solution into the core of the business so that it becomes part of the culture and day-to-day operations of the department.

Although business intelligence $(\mathrm{BI})$ is often synonymous with technology, $\mathrm{BI}$ includes the people, processes, and technologies that turn data into insights that further drive business decisions and actions (Wixom et al., 2013). Therefore, the solution model is cyclical in nature indicating that the process is constantly evolving and changing as business needs are identified and business problems are solved (Hobek et al., 2009). The model is separated into three sections: people, process, and technology. Each section contains key components that represent critical success factors in the adoption of a business intelligence program (Yeoh \& Koronios, 2010). Within each key component, the model also identifies specific tasks and initiatives that need to be included throughout the process in order for a successful execution of the solution. Each component and specific task is a necessary part to the overall success of the BI initiative.

\section{Figure 1: Conceptual Model}

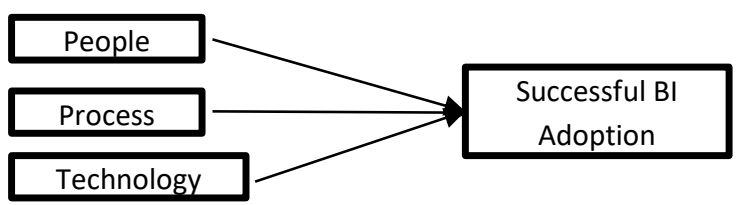

People/organizational: Business intelligence $(\mathrm{BI})$ requires delivering data to the right people at the right time. $\mathrm{BI}$ allows business users the ability to access and analyze data which enables them to solve important business problems and make informed business decisions that will ultimately provide a strategic benefit to the organization. In order to be successful, a BI program needs a combination of people including executive leaders, end users, IT personnel, and business sponsors. These individuals need to be equipped with cross-functional skills including a strong business understanding and good problem-solving skills. People within the organization are the heart of Bl.

Process: While BI is typically correlated with developing reports and creating executive dashboards or scorecards, BI is more complex and frequently involves changes to daily routines and processes. It involves cross-functional teams, technical complexities, and broader departmental challenges. Furthermore, investing in a Bl solution requires a significant change to the organizational culture and environment. Therefore, understanding the key components of the process dimension is critical to $\mathrm{Bl}$ success and improving $\mathrm{Bl}$ adoption rates. Technology: There are multiple organizational factors that can be attributed to the low BI adoption rates within businesses. One of those factors is related to BI capabilities or critical functionalities which include such things as user access, interaction with other systems, and flexibility with the BI system (Isik et al., 2012). 


\section{CONCLUSION}

Developing a business intelligence solution for an organization is not a project but rather a continuously evolving process that takes significant time and resources. It is not a one-time effort but instead requires on-going, continuous work. Organizations are continuing to invest in $\mathrm{BI}$ technologies while $\mathrm{BI}$ adoption rates among employees remain extremely low. Companies need to develop strategies that will improve the $\mathrm{Bl}$ adoption rate at both the individual and organizational level. Using a business model that focuses on identifying and solving one critical business need at a time and utilizing Analytic Advisors at the departmental level to collaborate between the business and IT will ultimately help to increase the low BI adoption rates. The proposed BI adoption model uses critical success factors in implementing a $\mathrm{BI}$ solution and applies it at a departmental level by applying various techniques and strategies to ensure that the BI initiative is accepted and embraced by both the end users and leadership. Central to this model is the business-IT hybrid resource or Analytics Advisor who performs a role as a trusted advisor, immersing themselves in the business unit to thoroughly understand the critical needs of the department. The proposed $\mathrm{BI}$ adoption model recognizes that a BI solution is a journey and a cyclical process that is constantly evolving, changing, and developing. Successful BI adoption means increasing efficiency, reducing errors, report automation, and using BI tools every day to facilitate the decision-making process as well as employing predictive analytics.

Businesses are investing in BI solutions more than ever yet end users are still not utilizing the tools and taking advantage of these solutions. The strategic and operational benefits of $\mathrm{BI}$ are numerous yet these benefits will not be realized without an increase in $\mathrm{BI}$ adoption rates. The solution presented in this paper provides an organization with a business model that incorporates critical success factors at the departmental level through the use of an Analytics Advisor who works within the department to identify critical business needs and opportunities. Working with a $\mathrm{Bl}$ team and collaborating with department leadership, the Analytics Advisor creates and successfully implements a $\mathrm{BI}$ solution through an iterative and agile process. This study has demonstrated how an organization can increase its $\mathrm{BI}$ adoption rates by developing solutions at a smaller level, one department at a time. As other departments within the organization see the successful results from implementing a BI solution, they will be encouraged to implement a BI program that will provide value and a competitive advantage by improving the timeliness and quality of the decision-making process. This will ultimately lead to the overall improved success of the organization as a whole.

\section{REFERENCES}

Boyton, J., Ayscough, P., Kaveri, D., Chiong, R. (2015). Suboptimal business intelligence implementations: understanding and addressing the problems. Journal of Systems \& Information Technology, 17(3), 307-320.

Hobek, R., Ariyachandra, T. R., Frolick, M. N. (2009). The importance of soft skills in business intelligence implementations. Business Intelligence Journal, 14(1), 28-36.

Hou, C. (2012). Examining the effect of user satisfaction on system usage and individual performance with business intelligence systems: an empirical study of Taiwan's electronics industry. International Journal of Information Management, 32, 560-573.

Isik, O., Jones, M. C., Sidorova, A. (2012). Business intelligence (BI) success and the role of BI capabilities. Intelligent Systems in Accounting, Finance \& Management, 18(4), 161- 176.

LaValle, S., Lesser, E., Shockley, R., Hopkins, M. S., Kruschwitz, N. (2011). Big data, analytics and the path from insights to value. MIT Sloan Management Review, 52(2), 21-31.

Mettler, T., Vimarlund, V. (2009). Understanding business intelligence in the context of healthcare. Health Informatics Journal, 15(3), 254264.

Perez, A. (2015). Seven best practices to make BI adoption pervasive. Business Intelligence Journal, 20(3), 43-58.

Stangarone, J. (2015). 7 practical ways to improve BI user adoption [Web log post]. Retrieved from http://www.mrcproductivity.com/blog/2015/03/7-practical-ways-to-improve-bi- user-adoption/

Williams, S., Williams, N. (2003). The business value of business intelligence. Business Intelligence Journal, 8(4), 30-39.

Wixom, B. H., Watson, H. J., Werner, T. (2011). Developing an enterprise business intelligence capability: the Norfolk Southern journey. MIS Quarterly Executive, 10(2), 61-71.

Wixom, B. H., Yen, B., Relich, M. (2013). Maximizing value from business analytics. MIS Quarterly Executive, 12(2), $111-123$.

Woodside, J. (2011). Business intelligence best practices for success. Proceedings of the International Conference on Information management \& Evaluation, 556-562.

Yeoh, W., Koronios, A., Gao, J. (2008). Managing the implementation of business intelligence systems: a critical success factors framework. International Journal of Enterprise Information Systems, 4(3), 79-94.

Yeoh, W., Koronios, A. (2010). Critical success factors for business intelligence systems. Journal of Computer Information Systems, 50(Pt. 3), 23-32.

Yogev, N., Even, A., Fink, L. (2013). How business intelligence creates value: an empirical investigation. International Journal of Business Intelligence Research, 4(3), 16-31.

Yoon, T. E., Ghosh, B., Jeong, B. (2014). User acceptance of business intelligence (BI) application: technology, individual difference, social influence, and situational constraints. Hawaii International Conference on System Sciences, 53758-3766. 